\title{
Investigation of the Au-Ge-Ni and Au-Ge-Pt system used for alloyed contacts to GaAs
}

\author{
M. Wittmer, T. Finstad, and M-A. Nicolet \\ California Institute of Technology, Pasadena, California 91125 \\ (Received 10 February 1977; accepted 28 March 1977)
}

\begin{abstract}
Widely used metallization schemes for alloyed contacts to $n$-type $\mathrm{GaAs}$ consist of a $\mathrm{Au}-\mathrm{Ge}$ alloy with a cover layer of $\mathrm{Ni}$ or Pt. We have studied the interaction of these elements $(\mathrm{Au}-\mathrm{Ge}$ and $\mathrm{Ni}, \mathrm{Au}-\mathrm{Ge}$ and $\mathrm{Pt})$ upon heat treatment on an inert substrate. Our results show that $\mathrm{Ni}$ and $\mathrm{Pt}$ play an active role in contact formation. During heat treatment the $\mathrm{Ge}$ diffuses out of the $\mathrm{Au}$ into the $\mathrm{Ni}$ or Pt layer, respectively, where it forms stable compounds. Due to the fact that $\mathrm{Ni}$ and $\mathrm{Pt}$ act as a sink for Ge the composition and, as it is shown, the uniformity of the heat-treated layers depend on the ratio of the amount of evaporated Ge to $\mathrm{Ni}$ or to Pt.
\end{abstract}

PACS numbers: $73.40 . \mathrm{Ns}, 81.40 . \mathrm{Gh}$

\section{INTRODUCTION}

Though the electrical properties of $\mathrm{Au}-\mathrm{Ge}-\mathrm{Ni}$ and $\mathrm{Au}-\mathrm{Ge}-\mathrm{Pt}$ contacts have been studied in the past, only little is known about the reaction mechanism of these contacts during the alloying process on GaAs. ${ }^{1,2}$ This is due to the fact that the five-element systems $\mathrm{GaAs}-\mathrm{Au}-\mathrm{Ge}-\mathrm{Ni}$ and $\mathrm{GaAs}-\mathrm{Au}-\mathrm{Ge}-\mathrm{Pt}$ are very complicated from a point of view of metallurgy. Therefore we simplified the situation and investigated the metallurgy of the Au-Ge-Ni and Au-Ge-Pt system without any interaction with $\mathrm{GaAs}$ by using an inert substrate. The results may help to understand what happens when these contact layers are alloyed to a GaAs substrate. In this communication we give a brief summary of our investigations. $A$ detailed report of the $\mathrm{Au}-\mathrm{Ge}-\mathrm{Ni}$ system is published elsewhere. ${ }^{3}$ Our investigation on the $\mathrm{Au}-\mathrm{Ge}-\mathrm{Pt}$ system is part of a survey we are undertaking on similar triple-layer systems.

Successive films of $\mathrm{Au}-\mathrm{Ge}-\mathrm{Ni}$ in one case and $\mathrm{Au}-\mathrm{Ge}-\mathrm{Pt}$ in the other case were evaporated with an electron gun at pressures of $10^{-6}$ Torr $\left(10^{-4} \mathrm{~Pa}\right)$ on $\mathrm{SiO}_{2}$ substrates. Small samples were annealed in a vacuum of $5 \times 10^{-7}$ Torr $(6 \times$ $10^{-5} \mathrm{~Pa}$ ) at $450^{\circ} \mathrm{C}$ for $5 \mathrm{~min}$. The samples were then investigated by $2-\mathrm{MeV}^{4} \mathrm{He}^{+}$backscattering spectrometry and glancing-angle $x$-ray diffraction.

\section{RESULTS}

\section{Au-Ge-Ni system}

Figure 1(a) shows the backscattering spectrum of an asdeposited sample of the structure $\mathrm{SiO}_{2} / \mathrm{Ge} / \mathrm{Au} / \mathrm{Ni}$. For simplicity, the low-energy part of the spectrum containing the signal of the $\mathrm{SiO}_{2}$ substrate has been omitted. The vertical arrows indicate the energy of ${ }^{4} \mathrm{He}^{+}$particles scattered from surface atoms of the corresponding element. The sample annealed at $450^{\circ} \mathrm{C}$ for $5 \mathrm{~min}$ has the backscattering spectrum shown in Fig. 1(b). The comparison with Fig. 1(a) shows that after annealing, the Ge signal at low energies has disappeared and that the spectrum shows a step at the energy corre- sponding to the surface location of $\mathrm{Ge}$, indicating that $\mathrm{Ge}$ has appeared in the surface layer. Therefore, we assume that $\mathrm{Ge}$ diffuses through the Au and mixes with the Ni to form compounds. The presence of these compounds was independently revealed by glancing-angle $x$-ray diffraction. This can also be established with backscattering spectrometry by etching off the top $\mathrm{Ge}-\mathrm{Ni}$ layer in dilute $\mathrm{HNO}_{3}$, which does not attack Au. Figure 1(c) shows the backscattering spectrum of the

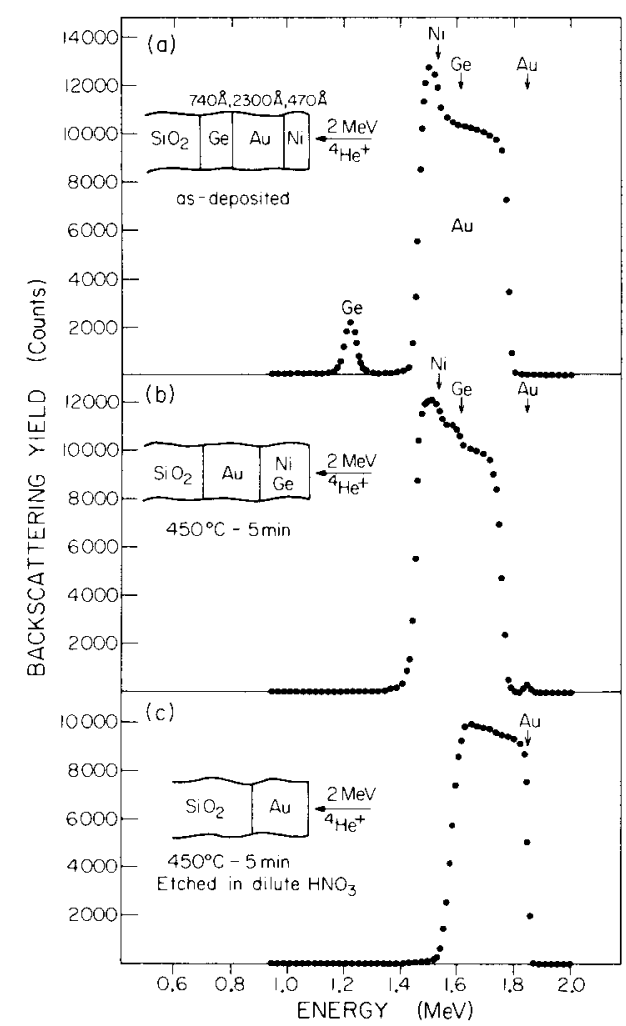

FIG. 1. 2-MeV ${ }^{4} \mathrm{He}^{+}$backscattering spectra of $\mathrm{a} \mathrm{SiO}_{2} / \mathrm{Ge} / \mathrm{Au} / \mathrm{Ni}$ sample. The spectra of the substrate has been omitted and the vertical arrows indicate the energy of He particles scattered from surface atoms of the corresponding elements. (a) as-deposited, (b) annealed at $450^{\circ} \mathrm{C}$ for $5 \mathrm{~min}$., (c) same as (b) but $\mathrm{Ge}-\mathrm{Ni}$ layer etched off in dilute $\mathrm{HNO}_{3}$. 


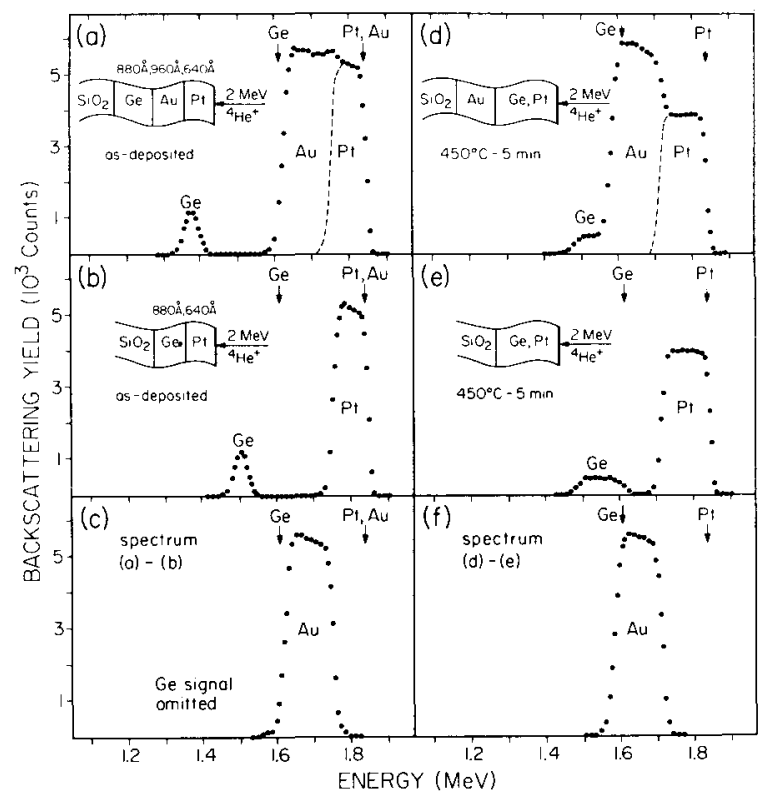

FIG. 2. 2-MeV ${ }^{4} \mathrm{He}^{+}$backscattering spectra of two samples of the same wafer of composition $\mathrm{SiO}_{2} / \mathrm{Ge} / \mathrm{Au} / \mathrm{Pt}$. The $\mathrm{SiO}_{2} / \mathrm{Ge} / \mathrm{Pt}$ sample was obtained by protecting part of the wafer with a shutter during the Au evaporation. The spectrum of the substrate has been omitted and the vertical arrows indicate the energy of He particles scattered from surface atoms of the corresponding elements. (a) $\mathrm{SiO}_{2} / \mathrm{Ge} / \mathrm{Au} / \mathrm{Pt}$ sample as-deposited, (b) $\mathrm{SiO}_{2} / \mathrm{Ge} / \mathrm{Pt}$ sample as-deposited, (c) spectrum (b) subtracted from spectrum (a) to reveal the Au signal, (d) sample of (a) annealed at $450^{\circ} \mathrm{C}$ for $5 \mathrm{~min}$., (e) sample of (b) annealed at $450^{\circ} \mathrm{C}$ for 5 min., (f) spectrum (e) subtracted from spectrum (d).

etched sample. Only the Au signal is left. The absence of any $\mathrm{Ge}$ signal demonstrates that there is no Ge dissolved in the $\mathrm{Au}$ within the resolution limit of better than $0.5 \%$. Thus all the $\mathrm{Ge}$ has been absorbed in the Ni layer.

The investigation of a sample of the composition $\mathrm{SiO}_{2} /$ $\mathrm{Ni} / \mathrm{Au} / \mathrm{Ge}$ showed that Ge diffuses also from a location at the surface of the triple layer through the Au to form compounds with a Ni film lying under the $\mathrm{Au}$ film on the $\mathrm{SiO}_{2}$ substrate. The phases of the compounds were identified with glancing-angle $\mathrm{x}$-ray diffraction as $\mathrm{Ni}_{2} \mathrm{Ge}$ and $\mathrm{NiGe}$.

As long as all the $\mathrm{Ge}$ can be accommodated by the $\mathrm{Ni}$, the layer as a whole remains uniform. However, if more Ge is used than can be absorbed by the $\mathrm{Ni}$ in form of $\mathrm{NiGe}$, the layer becomes laterally nonuniform.

\section{Au-Ge-Pt system}

In practice, the $\mathrm{Ni}$ top layer is sometimes replaced by $\mathrm{Pt}$ and it is interesting to know whether the same interactions take place with Pt during the heat treatment as are observed in the case of the $\mathrm{Au}-\mathrm{Ge}-\mathrm{Ni}$ system.

Figure 2(a) shows the backscattering spectrum of an asdeposited sample of the composition $\mathrm{SiO}_{2} / \mathrm{Ge} / \mathrm{Au} / \mathrm{Pt}$. During the Au evaporation, part of the wafer was protected with a shutter. The backscattering spectrum of that part is shown in Fig. 2(b). From these two spectra the thickness of the Pt film can be calculated. This is not possible from Fig. 2(a) alone because $\mathrm{Pt}$ and $\mathrm{Au}$ can not be distinguished in a backscattering spectrum due to the similar mass of these two atoms. If we subtract the Pt signal of Fig. 2(b) from the Pt and Au signal of Fig. 2(a), we get the signal shown in Fig. 2(c), which is that of the Au contained in the spectrum of Fig. 2(a). From this signal we can calculate the exact thickness of the Au film. The annealed sample with the Au layer has the backscattering spectrum of Fig. 2(d). Again we see that the Ge signal has disappeared from its original position. The annealed sample without the Au layer has the backscattering spectrum given in Fig. 2(e). By comparing this spectrum against that of Fig. 2(b), it is readily seen that the Ge and Pt are uniformly mixed in this case. Glancing-angle $\mathrm{x}$-ray diffraction reveals that platinum-germanides have been formed. If we subtract the spectrum of Fig. 2(e) from that of Fig. 2(d), the spectrum of Fig. 2(f) results. The signal obtained in this fashion has exactly the same shape as that of the Au in Fig. 2(c). This therefore indicates that the Au film remains essentially unaltered and that no appreciable amount of $\mathrm{Ge}$ is dissolved in the Au film. All the Ge formed compounds with the Pt as if the Au film was not present.

Laterally uniform $\mathrm{Au}-\mathrm{Ge}-\mathrm{Pt}$ contact layers are obtained after annealing if the atomic percentage of $\mathrm{Ge}$ is less than that of $\mathrm{Pt}$. If more Ge is present initially than can be absorbed by the $\mathrm{Pt}$, the layer becomes nonuniform.

\section{CONCLUSION}

In conclusion, we have shown that $\mathrm{Ni}$ and $\mathrm{Pt}$ behave in similar fashion as far as the present study is concerned. With limited amounts of $\mathrm{Ge}$ present, the Au plays a passive role during heat treatment. Ge diffuses through the Au and forms compounds with both the Ni or the Pt. The uniformity of the heat-treated layers depend on the ratio of the amount of evaporated $\mathrm{Ge}$ to $\mathrm{Ni}$ or $\mathrm{Pt}$.

\section{ACKNOWLEDGMENTS}

We are grateful to J. W. Mayer for his many fruitful comments and to R. Gorris and J. Mallory for their technical assistance.

The work was supported by the Defense Advanced Research Projects Agency, the Department of Defense, and monitored by Air Force Cambridge Research Laboratories under Contract No. F19628-75-C-0113.

${ }^{1}$ K. Ohata and M. Ogawa, "Degradation of gold-germanium ohmic contact to $n$-GaAs," 12th Annual Proc. of the IEEE Reliability Physics Symposium, Las Vegas, May 1974.

${ }^{2}$ G. Y. Robinson, Solid-State Electron. 18, 331 (1975).

${ }^{3}$ M. Wittmer, R. Pretorius, J. W. Mayer, and M-A. Nicolet, Solid-State Electron. in press (1977). 